\title{
A MODEL FOR FATIGUE CRACK GROWTH IN THE PARIS REGIME UNDER THE VARIABILITY OF CYCLIC HARDENING AND ELASTIC PROPERTIES
}

\author{
Tayeb Kebir ${ }^{1}$, Mohamed Benguediab ${ }^{1}$, Abdellatif Imad ${ }^{2}$ \\ 1) Department of Mechanical Engineering, Faculty of Technology, Laboratory \\ of Materials and Reactive Systems (LMRS), University of Sidi Bel-Abbes, Algeria \\ 2) Polytech'Lille1, Laboratory of Mechanical of Lille (LML), University of Lille1, \\ France
}

\begin{abstract}
Over the last 60 years, several models have been developed governing different zones of fatigue crack growth from the threshold zone to final failure. The best known model is the Paris law and a number of its based on mechanical, metallurgical and loading parameters governing the propagation of cracks. This paper presents an analytical model developed to predict the fatigue crack propagation rate in the Paris regime, for different material properties, yield strength $\left(\sigma_{v}\right)$, Young's modulus $(E)$ and cyclic hardening parameters $\left(K^{\prime}, n^{\prime}\right)$ and their influence by variability. The cyclic plastic deformation at a crack tip or any other cyclic hardening rule may be used to reach this objective, for to investigate this influence, these properties of the model are calibrated using available experimental data in the literature. This FCGR model was validated on Al-alloys specimens under constant amplitude load and shows good agreement with the experimental results.
\end{abstract}

Keywords: cyclic plastic strain, elastic properties, cyclic hardening parameters, Young's modulus, variability, crack tip, fatigue crack growth, constants of the Paris law, Al-alloys.

\section{INTRODUCTION}

The fatigue crack growth resistance of a material depends upon a number of factors, such as its composition, mechanical properties and heat treatment conditions, external loading and the environment. Several theoretical models have been proposed to predict the fatigue crack growth (FCG) process using solid mechanics-based theoretical tools and fundamental mechanical properties.

The understanding of the mechanisms governing fatigue crack growth has made significant advances since Paris [1] proposed a law that relates the crack growth rate $d a / d N$ and the stress intensity factor range $\Delta K$ : 


$$
\frac{d a}{d N}=C(\Delta K)^{m}
$$

Experimentally, the exponent $m$ given in the Paris law can vary between 2 and 6 for most metals and alloys [2]. In Paris law there is no evidence of the mechanical parameters effects. Several authors have attempted to integrate other parameters such as the $R$-ratio $\left(R=\sigma_{\min } / \sigma_{\max }\right)$, critical stress intensity factor $K_{I C}$, etc. Walker [3] reported on the effect of the $R$-ratio on crack propagation for aluminum alloys, concluding that increasing $R$ resulted in an increased growth rate. For according the model of Walker [3], the influence of the mean stress and R-ratio on fatigue crack propagation in aluminum alloys was suggested by [4]. Paris and Walker equation works well in the Paris region of crack growth, but does not address the asymptotic behavior in the unstable region. To address this behavior, Forman [5] proposed a new relationship that reflects the fracture by incorporating the stress ratio and the critical stress intensity factor $K_{I C}$ given by:

$$
\frac{d a}{d N}=\frac{C(\Delta K)^{m}}{(1-R)\left(K_{I C}-K_{\max }\right)}
$$

As $K_{\max }$ approaches $K_{I C}$, the denominator approaches zero and $d a / d N$ tends toward infinity. This equation has been verified many times for aluminum alloys [3], [6]-[8].

Elber [9] was the first researcher to introduce the concept of crack closure in fatigue crack growth. This concept reveals the premature contact of the crack faces during the unloading portion of the loading cycle while some tensile load is still applied. Elber found that the fatigue crack growth rate was a function of a new factor he called effective stress intensity factor range $\Delta K_{\text {eff }}$.

In general, the phenomenon of crack closure has been widely accepted as a critical mechanism influencing many aspects of the behavior of fatigue cracks in metallic materials, including variable amplitude loading [10], R-ratio effects, crack size, microstructure [11], cyclic plastic strain [12], thermo-mechanical [13], environment [14], residual stress [15] and the magnitude of the fatigue threshold [16]. The higher fatigue crack growth rates and lower thresholds in the alloy of Magnesium may be attributed to a much smoother fracture surface morphology and lower roughness-induced crack closure and crack deflection [17]. The effects of grain size, also spanning the fatigue crack growth [18].

Besides this mechanically based concept, other approaches based on energy consideration [19]-[21] or on micro mechanisms acting at the crack tip have been developed. In these approaches some authors attempted to express the 
crack growth rate by explaining the effects of different parameters by means of theoretical models based on the low cycle fatigue and cyclic strain hardening [19], [22].

Noroozi et al. [23], [24] proposed the FCG equation in terms of a unified twoparameter driving force assuming predominately plastic material deformation at the crack tip while modeling the high fatigue crack growth rate, and the elastic behavior for the near threshold fatigue crack growth. Fatigue crack growth expressions derived for the two different material behaviors [23], [24].

Duggan [25] focused on the deformation of a volume element located at the crack-tip. This volume element is only subjected to elastic deformations and so the effect of softening or of hardening is disregarded. Duggan [25] has assumed that propagation occurs when the Manson-Coffin and Miner laws are satisfied at the same time. He expressed the crack growth rate in terms of the elastic modulus $E$, toughness $K_{I C}$, and ductility $\left(\sigma^{\prime}{ }_{f}, \varepsilon^{\prime}{ }_{f}\right)$ coefficient and exponent:

$$
\frac{d a}{d N}=\frac{1}{\varepsilon^{\prime}{ }_{f}}\left[\frac{2 \sqrt{\pi / 32}}{\sigma^{\prime}{ }_{f} E\left(K_{I C}-K_{\max }\right)}\left(1-\frac{\Delta K}{K_{I C}}\right)\right]^{\frac{1}{\varepsilon^{\prime_{f}}}} \Delta K^{\left(\frac{2}{\varepsilon_{f}^{\prime}}\right)}
$$

Radon [26] proposed a crack growth model for the near threshold region $\left(\Delta K_{t h}\right)$ which incorporates mechanical, cyclic and fatigue properties of the material, and a cyclic plastic strain $\left(\Delta \varepsilon_{p}\right)$ based on the failure criterion. He also introduced an effective stress intensity factor range $\left(D K_{\text {eff }}\right)$ which characterizes the crack tip opening displacement and the strains immediately ahead of the crack tip. The cyclic plastic strain range $\left(\Delta \varepsilon_{p}\right)$ at the crack front is given by the expression:

$$
\Delta \varepsilon_{p}=\frac{2 \sigma_{y}}{E}\left[\frac{\Delta K^{2}}{4 \pi\left(1+n^{\prime}\right) \sigma_{y}^{2} a}\right]^{1 / 1+n^{\prime}}
$$

Where: $\sigma_{y}, E$ and $n$ ' are the yield strength, Young's modulus and cyclic hardening exponent, respectively.

Radon [26] obtained a simple model of cyclic crack propagation in the threshold region and developed an expression for the crack growth rate, given below:

$$
\frac{d a}{d N}=\frac{2^{n^{\prime}-1}(1-2 v)^{2}}{\pi\left(1+n^{\prime}\right)} \frac{\left(\Delta K_{e f f}^{2}-\Delta K_{t h}^{2}\right)}{\sigma_{y}^{1-n^{\prime}}\left(E . \varepsilon_{f}\right)^{1+n^{\prime}}}
$$


Lal et al. [27] developed a model that integrates some notions, such as the effective strain intensity factor defined by Elber. These authors calculated the monotonous and cyclic plasticized zones:

$$
r_{p m}=\left(\frac{\Delta K}{2 \cdot \sigma_{e}}\right)^{1+n^{\prime}} \cdot a^{1-n^{\prime} / 2}
$$

This relationship is obtained from the calculation performed under a simple traction replacing the monotonous work hardening exponent by the cyclic hardening exponent and $K$ by $\Delta K$.

If we apply Elber's hypothesis, Lal et al. [27] presumed that a single part of a cycle was necessary to close the crack, and thus to create the plasticized zone, the other part of the cycle inducing the grounding of the crack lips. Then they used the definition of the monotonous plastic zone that was calculated previously, and by replacing $\Delta K$ with $\Delta K_{\text {eff }}$ they obtained the dimensions of the cyclic plasticized zone:

$$
r_{p c}=r_{p m} \cdot U^{1+n^{\prime}}
$$

Using the hypothesis suggested by Tomkins [28], the fatigue crack growth model is described as the function of $\Delta \varepsilon_{p}$ and $r_{p c}$ :

$$
\frac{d a}{d N}=\Delta \varepsilon_{p} \cdot r_{p c}
$$

Where the Tomkins model often used for low cycle fatigue tests under significant plasticity could not explain the results for the variation in crack length nor the variation in loading parameters.

In order to calculate $\Delta \varepsilon_{p}$, they used the equation $\Delta \sigma_{N}=K^{\prime} .\left(\Delta \varepsilon_{p} / 2\right)^{n^{\prime}}$ which describes the hysteresis loops, where: $\Delta \sigma_{N}$ is the variation of stress in the ligament. They expressed the plastic deformation as an amplitude function of the stress intensity factor:

$$
\Delta \varepsilon_{p}=\left[\frac{\Delta K}{\sqrt{\pi \cdot a} \cdot K^{\prime}(1-a / w)}\right]^{1 / n}
$$

The propagation rate is then equal to:

$$
\frac{d a}{d N}=\frac{(0.5 U)^{1+n^{\prime}}(\sqrt{w})^{1-n^{\prime}-1 / n^{\prime}}}{\left(K^{\prime} \sqrt{\pi}\right)^{1 / n^{\prime}} \sigma_{y}^{1+n^{\prime}}}\left(\frac{(\sqrt{a / w})^{n^{\prime}\left(1-n^{\prime}\right)}}{\sqrt{a / w}(1-a / w)}\right)^{1 / n^{\prime}} \Delta K^{1+n^{\prime}+1 / n^{\prime}}
$$


Two of the parameters of equation (10): (a) and ( $w$ ), are geometric and easily measurable. The other three $U, \sigma_{e}, K^{\prime}$ and $n^{\prime}$ depend on the material. The rate decreases when the elasticity limit increases, and it increases if $\mathrm{R}$ increases, which matches the experimental results. The parameters $\sigma_{e}, K^{\prime}$ and $n^{\prime}$ might be easily calculated, but $U$ (except for some aluminum alloys) is less well known. However, there is not enough experimental evidence to determine the variation of the rate as a function of crack length. This equation has been verified for many materials (aluminum, mild steel, stainless steel and copper) and the calculated and measured values of the parameters $C$ and $m$ of Paris' law agree with it.

Models based on the calculation of the crack tip with hardening have been developed by many researchers [19], [26], [27], [29], [30]. These models rely on calculating the plasticized monotonic and cyclical areas created by the cyclical stress; it is generally assumed that the crack propagation is proportional to the energy lost in the plasticized zones. All these models use hysteresis loops to evaluate plastic deformation. The macroscopic behavior characterized by the hysteresis loop is introduced into these models to describe the microscopic behavior at the crack tip.

In a recent study, Shi et al. [30], [31] have developed an analytical fatigue crack growth rate model based on the crack closure expression, effective cyclic plastic zone and the low cycle fatigue properties. Comparative results demonstrate that the fatigue crack growth rate estimated by the theoretical model closely approximates the experimental results. The predicted model is limited to isotropic materials.

Tzamtzis et al. [32] have developed a model to predict the fatigue crack propagation rate under mode I loading in 2024 aluminum alloy. The model considers local cyclic hardening behavior in the heat affected zone (HAZ) to analyze crack growth. The analytical results showed that cyclic hardening at the crack tip can be used successfully with this model to predict FCG in a material at overage condition associated with a location in the Friction Stir Welding heat affected zone (HAZ).

$$
\frac{d a}{d N}=a^{\frac{2 c+3}{2 c+2}}\left[\frac{4 \sqrt{\pi} E 2^{(c+1 / 2)}\left(1-n^{\prime}\right) \varepsilon_{f}^{\prime}}{(1-v) K_{I C}^{2}\left(1+n^{\prime}\right)}\right]^{1 /(c+1)} . \Delta K^{1 /(c+1)}
$$

where, parameters $K_{I C}, c, \varepsilon_{,}^{\prime}, E$, can be determined experimentally.

All these models cannot be applied generally; each describes a situation under the influence of certain intrinsic parameters (Young's modulus, grain size, yield strength, toughness) and extrinsic (specimen dimensions, and environmental 
effects). They become unsuitable as soon as a parameter of the experience varies. The most of the proposed models of fatigue growth remain essentially empirical, and hence their constants often vary more than expected.

In this paper, we propose an analytical model relating the fatigue crack propagation rate in the Paris regime with different material properties effects at the crack tip, such as cyclic hardening $\left(K^{\prime}, n^{\prime}\right)$ parameters and elastics properties $\left(E, \sigma_{y}\right)$, and their influence by variability, based on the properties calibrated using available experimental data in the literature. This study introduces the hardening parameter $\left(K^{\prime}, n^{\prime}\right)$ directly in the Paris law parameters $(C, m)$, which the authors consider as an advantage. The details are presented below.

\section{ANALYTICAL MODEL}

This work focuses on a model of fatigue crack growth, using the assumptions of plastic strain at the fatigue crack tip and the Tomkins model [28]. We have developed a model for fatigue crack growth that varies according to elastic $\left(E, \sigma_{v}\right)$ and cyclic hardening $\left(K^{\prime}, n^{\prime}\right)$ properties.

The modeling of fatigue crack growth requires good understanding of the evolution of the behavior of a material under cyclic loading. Thus, the cyclic plastic stress/strain response at fatigue crack tips was studied [33], [34], as described in Figure 1.

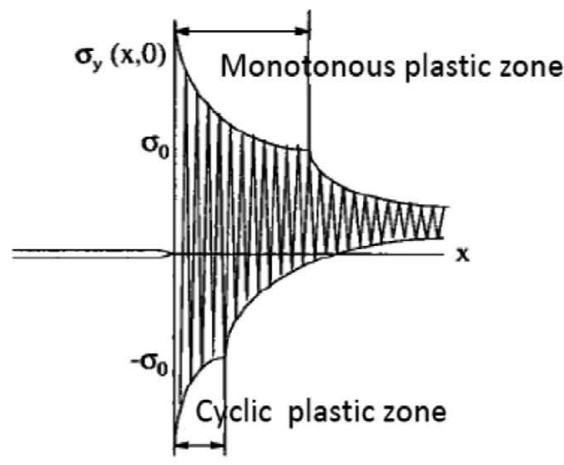

(a)

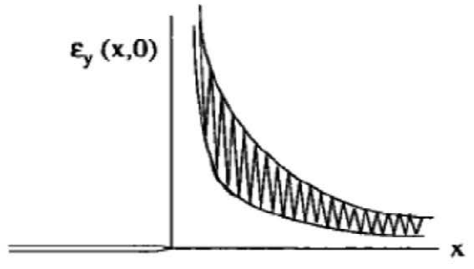

(b)

Fig. 1. Evolution for stress vertical component (a) and strain (b) versus crack growth

The cyclic plastic zone size at a crack tip can be written as [35] :

$$
r_{c}=\frac{1}{2 \pi \sigma_{v}^{2}}(\Delta K)^{2}
$$


Replacing $\Delta K$ obtained from equation (9) and introducing into (12), expression of the radius of the plastic zone is:

$$
r_{c}=\frac{a}{2}\left(\frac{K^{\prime}(1-a / w)}{\sigma_{y}}\right)^{2}\left(\Delta \varepsilon_{p}\right)^{2 n^{\prime}}
$$

Substituting equation (13) into equation (8), the crack propagation is given by:

$$
\frac{d a}{d N}=\frac{a}{2}\left(\frac{K^{\prime}(1-a / w)}{\sigma_{y}}\right)^{2}\left(\Delta \varepsilon_{p}\right)^{\left(2 n^{\prime}+1\right)}
$$

Introducing equation (4) into equation (14), the relation can be written in the form similar to the Paris law Eq.(1) multiplied by factor $\beta$ :

$$
\frac{d a}{d N}=\beta C(\Delta K)^{m}
$$

where the constants $\beta, C$ and $m$ are defined as:

$$
\begin{gathered}
\beta=\frac{(1-a / w)^{2}}{a^{n^{\prime}\left(1+n^{\prime}\right)}} \\
C=\frac{\left(2^{n^{\prime}} K^{\prime}\right)^{2} \sigma_{y}^{\left(2 n^{\prime 2}-3 n^{\prime}-3\right)\left(1+n^{\prime}\right)}}{\left(\left(4 \pi+4 \pi n^{\prime}\right)^{1 /\left(1+n^{\prime}\right)} E\right)^{2 n^{\prime}+1}} \\
m=\frac{4 n^{\prime}+2}{1+n^{\prime}}
\end{gathered}
$$

\section{APPLICATION AND INTERPRETATION}

The theoretical model developed represents the fatigue crack growth based on cyclic hardening parameters $\left(K^{\prime}, n^{\prime}\right)$ and elastics proprieties $\left(E, \sigma_{y}\right)$ due to the plasticity at the crack tip. Table 1 shows these different parameters found in the literature for two A-alloys studied (2024 T3 and 7075 T6), which were used in the model to obtain the validation and comparison with experimental results [36], [37]. In addition, the variability of the elastics properties and cyclic hardening parameters is evaluated to show their influence on fatigue crack growth. 
Table 1. Material and cyclic properties of Al-alloys

\begin{tabular}{|c|c|c|c|c|c|}
\hline Alloys & E [GPa] & oy [MPa] & K' [MPa] & n' & Refs \\
\hline \multirow{5}{*}{$2024 \mathrm{~T} 3$} & 70.3 & 429 & 843 & 0.109 & {$[38]$} \\
& 73 & 320 & 427 & 0.065 & {$[39]$} \\
& 73.1 & 445 & 576 & 0.042 & {$[32]$} \\
& 72 & 460 & 590 & 0.040 & {$[40]$} \\
\hline \multirow{7}{*}{$7075 \mathrm{~T} 6$} & 72.2 & 394 & 521 & 0.045 & {$[38]$} \\
& 71 & 466 & 864.1 & 0.0866 & {$[39]$} \\
& 71 & 517 & 913 & 0.090 & {$[40]$} \\
& 70.6 & 540 & 790 & 0.062 & {$[41]$} \\
& 71 & 469 & 977 & 0,106 & {$[42]$} \\
& 71.7 & 468.85 & 737.81 & 0.056 & {$[43]$} \\
& 71 & 469 & 781 & 0.088 & {$[30]$} \\
\hline
\end{tabular}

In order to validate the developed model, two applications were given when the compact type $\mathrm{C}(\mathrm{T})$ and center-cracked-tension $\mathrm{M}(\mathrm{T})$ specimens are used according to ASTM [44] code (E647-00) as shown in Figure 2, with the same applied loading defined in experimental tests [36], [37].

a)



b)

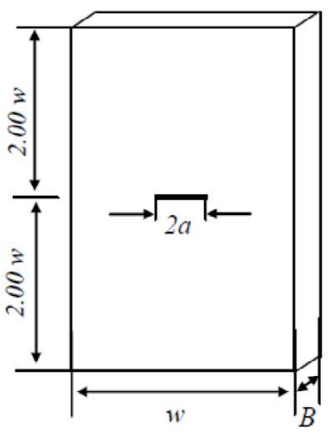

Fig. 2. Schematic of specimens, a) C(T), b) M(T)

The stress intensity factor range $\mathrm{D} K$ is computed using the applied force as follows:

$$
\Delta K=\frac{\Delta P}{B} \sqrt{\frac{\pi \alpha}{2 w} \sec \frac{\pi \alpha}{2}} \text { with } \alpha=(2 a / w) \text { for specimen } \mathrm{M}(\mathrm{T})[36]
$$

$$
\Delta K=\frac{\Delta P}{B} \sqrt{\pi a} f\left(\alpha^{\prime}\right) \text { with } \alpha^{\prime}=(a / w) \text { for specimen } \mathrm{C}(\mathrm{T})[35]
$$

where, $f\left(\alpha^{\prime}\right)=\frac{2+\alpha^{\prime}}{\left(1-\alpha^{\prime}\right)^{3 / 2}}\left[0.886+4.64\left(\alpha^{\prime}\right)-13.32\left(\alpha^{\prime}\right)^{2}+14.72\left(\alpha^{\prime}\right)^{3}-5.6\left(\alpha^{\prime}\right)^{4}\right]$ 
The amplitude loading is given by, $\Delta P=\left(P_{\max }-P_{\min }\right), B$ and $w$ are respectively the thickness and width of the tested specimens. The geometrical parameters and applied loads for specimens are defined in Table 2.

Table 2. Experimental conditions obtained for tested Al-alloys sample

\begin{tabular}{|c|c|c|c|c|c|c|}
\hline Al-alloy & $\mathbf{B}[\mathbf{m m}]$ & $\mathbf{w}[\mathbf{m m}]$ & $\mathbf{P}_{\max }[\mathbf{N}]$ & $\mathbf{P}_{\min }[\mathbf{N}]$ & Specimen & Refs \\
\hline $2024 \mathrm{~T} 3$ & 3.2 & 60.00 & 2700.0 & 270.00 & $\mathrm{C}(\mathrm{T})$ & {$[37]$} \\
\hline $7075 \mathrm{~T} 6$ & 3.18 & 102.03 & 1902.0 & 190.20 & $\mathrm{M}(\mathrm{T})$ & {$[36]$} \\
\hline
\end{tabular}

Firstly, the theoretical evaluation of the plastic zone size in the vicinity of the crack tip is handicapped by the distorted picture of the stress field in front of the fatigue crack. In these respects, the proposed approach has the advantage of being an "interpolation procedure to variability" between the elastic properties (yield strength $\sigma_{y}$, Young's modulus $E$ ) and cyclic hardening parameters $\left(K^{\prime}, n^{\prime}\right)$ within the fatigue crack growth rate, hence avoids the risk associated with the inevitable "extrapolation" nature of many other phenomenological but essentially empirical models. These works correctly modeled suggest a qualitative experimental verification, but the model, in the present form, remains essentially speculative.

In the tests of the model for fatigue crack growth rate (Eq. 15) developed by this work, it is of interest to take into account the crack growth effects caused by the different material properties such as Young's modulus $E$, yield strength $\sigma_{y}$ and cyclic hardening parameters $\left(K^{\prime}, n^{\prime}\right)$. The values of the materials properties listed in Table 1 are plotted against the experimental curves results [36], [37] for the alloys studied, 7075-T6 and 2024-T3, respectively. Figures 4 to 7 show that the experimental and computed values lie near a line drawn through the origin experimental data [36], [37] suggesting a good agreement between them, These plots confirms that fatigue crack growth in the constant $\Delta K$ occurred in the Paris regime at an $R$-ratio of 0.1 consistent with the results of [36], [37] for Al-alloys studied 7075-T6 and 2024-T3, respectively. However, our approach in this study is very direct and perhaps explains the influence of variability for different material properties in a more straightforward way. This variability of the parameters $\left(K^{\prime}, n^{\prime}, \sigma_{y}, E\right)$ allowed to predict their influence on fatigue crack growth, will be explained below.

The factor $\beta$ (Eq. 16) is dependent on the normalized crack size and the cyclic strain hardening exponent $(n$ ') this factor will be called crack size constant, so is observed by [27]. Figure 3 gives the variation of the factor $\beta$ as a function of crack growth for various values of $\left(n^{\prime}\right)$. It is observed that for all values of 
cyclic hardening exponent $\left(n^{\prime}\right)$, a decreasing of the factor $\beta$ along the crack propagation (a). Moreover, seems that when $\left(n^{\prime}<0.050\right)$, the factor $\beta$ becomes stable approximate along the crack $(a)$ about $(1.3 \geq \beta \geq 1.1)$ does effect little the crack propagation rate. So when $\left(n^{\prime}>0.050\right)$, this factor take an important value that the first, about $(1.7 \geq \beta \geq 1.2)$ is found the crack growth rates increase when cyclic hardening exponent $\left(n^{\prime}\right)$ increases. This behavior is in good agreement with the computed curve for identical conditions for Paris's law shown in the following figures.


a)

b)

Fig. 3. Variation of factor $\beta$ versus crack size with variability of cyclic hardening $n$ ', a) $2024 \mathrm{T3}$, b) $7075 \mathrm{T6}$

\subsection{Influence of cyclic hardening coefficient $\left(K^{\prime}\right)$}

Figures $4 \mathrm{a}-\mathrm{b}$ show the variability of the cyclic hardening coefficient $\left(\mathrm{K}^{\prime}\right)$ on the evolution of the fatigue crack growth versus the stress intensity factor range $(\Delta K)$ compared with experimental results [36], [37] for alloys studied 7075-T6 and 2024-T3, respectively. The influence of the cyclic hardening coefficient $\left(\mathrm{K}^{\prime}\right)$ is well marked on the evolution of the fatigue crack growth. It is noticed that the fatigue crack growth increases when the cyclic hardening coefficient increases. Several studies have been remarked this phenomenon [30], [32], [33], [37], [45].



a)

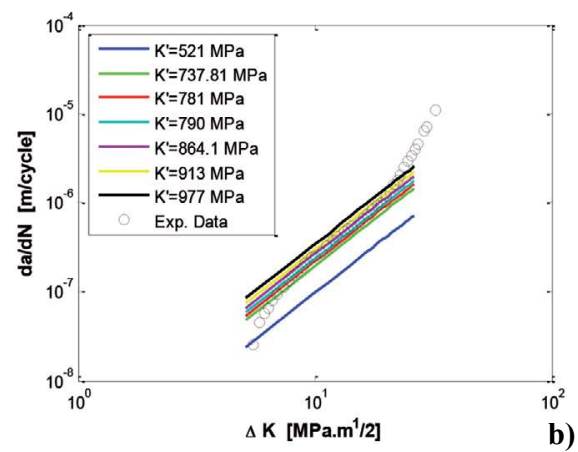

b)

Fig. 4. Fatigue crack growth rate versus stress intensity factor range, variability of cyclic hardening $K^{\prime}$, a) 2024 T3, b) 7075-T6 


\subsection{Influence of cyclic hardening exponent (n')}

Other, at the crack tip, in the course of a fatigue cycle, the cyclic plastic zone size effect thermal-mechanical modified material behavior, presents an important hardening. There exist evident influences of the cyclic hardening exponent $(n ')$ on the evolution of fatigue crack growth versus stress intensity factor range $\Delta K$. Tow Al-alloys (2024-T3 and 7075-T6) with various cyclic hardening exponent $(n ')$ level also analyzed using our proposed model compared with experimental results [36], [37], shown in figure 5a-b, that the fatigue crack growth rates $d a / d N$ are a linear function versus the stress intensity factor range $\Delta K$ for almost all cyclic hardening exponent $\left(n^{\prime}\right)$. This can be expected if the crack propagates according to the Paris law with respect to the cyclic hardening exponent $(n ')$. The influences to variability clearly of the cyclic hardening exponent $\left(n^{\prime}\right)$ increase when fatigue crack growth rate decrease. The hardening effect can be attributed to the influence of plastic strain at some point at the crack front to lead a higher magnitude of plastic strain which governing the evolution of crack growth $d a$ / $d N$ versus crack length [30], [32], [33], [37], [45].

For 7075-T6 Al-alloy and at the same stress intensity factor $\Delta K .=13 \mathrm{MPa} \cdot \mathrm{m}^{1 / 2}$, the FCGR decreases from 12.9E-7 m/cycle to 3.09E-7 m/cycle with an increase in the cyclic hardening exponent $\left(n^{\prime}\right)$ from 0.045 to 1.106 (about $50 \%$ of reduction in cyclic hardening exponent). But for 2024 T3, the FCGR decreases from $1.66 \mathrm{E}-7 \mathrm{~m} /$ cycle to $0.42 \mathrm{E}-7 \mathrm{~m} /$ cycle. In the present study, the developed model (FCGRs model) enclose the experimental using plastic strain energy and the hardening effect contrary to the study conducted by [20], [46]-[48] when the developed models enclose the experimental result with introduce plastic strain energy and the crack closure effect. The variability of the cyclic hardening exponent show a moderate effect on fatigue crack growth rates (FCGR) is significant for $7075 \mathrm{~T} 6 \mathrm{Al}$-Alloy comparatively to $2024 \mathrm{~T} 3 \mathrm{Al}-\mathrm{Alloy}$.
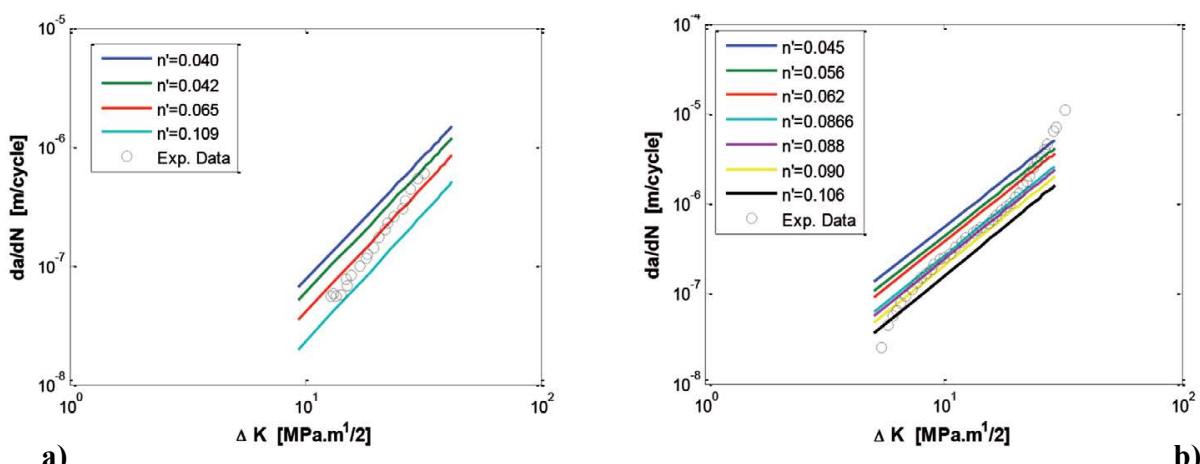

a)

Fig. 5. Fatigue crack growth rate versus stress intensity factor range, variability of cyclic hardening exponent ( $n^{\prime}$ ), a) 2024 T3, b) 7075 T6 


\subsection{Influence of cyclic yield strength $\left(\sigma_{y}\right)$}

Figure $6 \mathrm{a}-\mathrm{b}$ show the fatigue crack growth rate versus the stress intensity factor range with different values of yield strength into relationship (Eq.15). The influence to variability it seems clearly suitable thus the velocity of fatigue crack growth increase when the yield strength decreases [17], [32], [45], [47], [49]. However, we can say that the yield strength is an important parameter into this model for the fatigue crack growth rate (Eq.15). It confirms that the yield strength has stronger influence on the fatigue crack growth.


a)

Fig. 6. Fatigue crack growth rate versus stress intensity factor range, variability of yield strength $\sigma_{v}$, a) $2024 \mathrm{T3}$, b) $7075 \mathrm{T6}$

\subsection{Influence of Young's modulus (E)}

The fatigue crack growth rates for Aluminum alloys are much more rapid than those in steel for a given $\Delta K$ [35], [36], [45]-[47]. Figures 7a-b show the fatigue crack growth rate as a function the stress intensity range $\Delta K$ at different values of Young's modulus compared with the experimental results [36], [37] for the studied Al-alloys, 7075-T6 and 2024-T3, respectively.

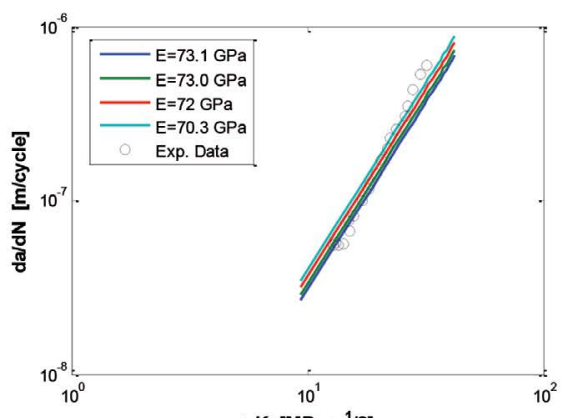

a)

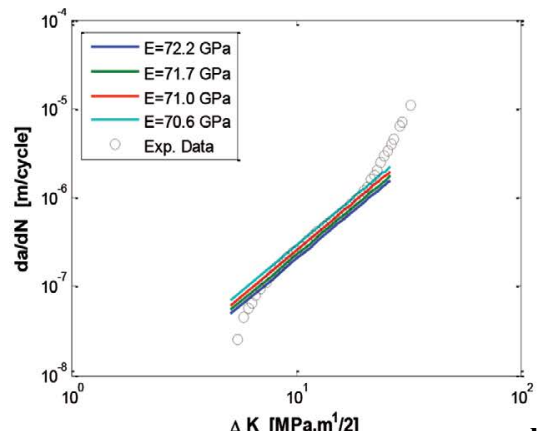

b)

Fig. 7. Fatigue crack growth rate versus stress intensity factor range, variability of cyclic Young's modulus E, a) 2024 T3, b) 7075 T6 
It is shown that there exist weakly influence by variability to this parameter such as the fatigue crack growth rate increases slowly when the Young's modulus decreases [45], [47], [49]. Others, observed the fatigue threshold models predict a strong influence of the elastic modulus [50], [51].

According to the differentiation between two types of behavior of Al-alloys introduced above table 2, the comparison of values of the material constants $C$ and $m$ between the obtained from this model (Eq.17 and 18) for different material properties studied $\left(K^{\prime}, n^{\prime}, \sigma_{y}, E\right)$ with the average values of literature realized a comparison acceptable for same $R$-ratio $\mathrm{R}=0.1$, as shown table 3 .

Table 3. Modeling and experimental values of parameters of Paris law

\begin{tabular}{|c|c|c|c|c|c|c|c|c|}
\hline \multirow{4}{*}{ Alloys } & \multicolumn{4}{|c|}{ Modeling values } & \multicolumn{3}{c|}{ Experimental values } \\
\hline \multirow{3}{*}{2024} & 0.040 & $6.2815 \mathrm{E}-10$ & 2.0769 & & $7.5100 \mathrm{E}-10$ & 2.01 & 0.1 & {$[37]$} \\
$\mathrm{T} 3$ & 0.042 & $5.9242 \mathrm{E}-10$ & 2.0806 & 0.1 & & & & \\
& 0.065 & $3.0259 \mathrm{E}-10$ & 2.1221 & & $2.6029 \mathrm{E}-10$ & 2.65 & 0.1 & {$[52]$} \\
& 0.109 & $8.4245 \mathrm{E}-11$ & 2.1966 & & & & & \\
& 0.045 & $4.1364 \mathrm{E}-09$ & 2.0861 & & & & & \\
$7075 \mathrm{~T} 6$ & 0.086 & $1.2328 \mathrm{E}-09$ & 2.1594 & 0.1 & & & & \\
& 0.056 & $3.0011 \mathrm{E}-09$ & 2.1061 & & & & & \\
& 0.062 & $2.5199 \mathrm{E}-09$ & 2.1168 & & $1.5739 \mathrm{E}-09$ & 2.19 & 0.1 & {$[36]$} \\
& 0.088 & $1.1837 \mathrm{E}-09$ & 2.1618 & & $1.6500 \mathrm{E}-10$ & 3.00 & 0.1 & {$[4]$} \\
& 0.090 & $1.1170 \mathrm{E}-09$ & 2.1651 & & & & & \\
& 0.106 & $7.0248 \mathrm{E}-10$ & 2.1917 & & & & & \\
\hline
\end{tabular}

Others, explained a decrease in the value of the exponent $(\mathrm{m})$ of the Paris law when the yield strength $\left(\sigma_{y}\right)$ increased [35], [53], [54]. So the exponent $(m)$ changes slightly at different temperatures, while constant $(C)$ for the Paris law changes with the temperature [55]. The analysis of these results shown in Table 3 also reveals an increase in the values of $(m)$ when the cyclic hardening exponent $\left(n^{\prime}\right)$ increases, and strictly inverted of constant $(C)$ of Paris law. Figure 8 shows the evolution of the constant $(C)$ for the Paris law versus the cyclic hardening coefficient $\left(K^{\prime}\right)$, we have remarked the variability of the coefficient $\left(K^{\prime}\right)$ increase, when the constant $(C)$ increases. 




Fig 9. Constant of Paris law $C$ versus cyclic hardening coefficient $K$ '

Using the relationship (Eq.17), the influence of elastic properties (Yield strength $\sigma_{y}$ and Young's modulus $E$ ) on the constant $C$ of the Paris law is shown in Fig. 9. The constant $C$ is plotted against the yield strength in (Fig. 9-a) explain that when the variability of yield strength $\left(\sigma_{y}\right)$ increase, when the constant $C$ decrease.

The Paris exponent $(m)$ decreases when increasing the Young's modulus, is remarked by [51], the (Fig 10-b) shows the evaluation of the constant $C$ versus the Young's modulus, seems linear, as approximate stable, the variability of Young's modulus is influenced little the constant $\mathrm{C}$.

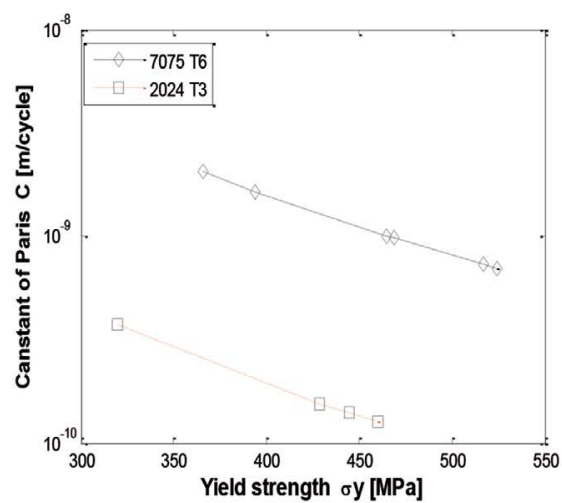

a)

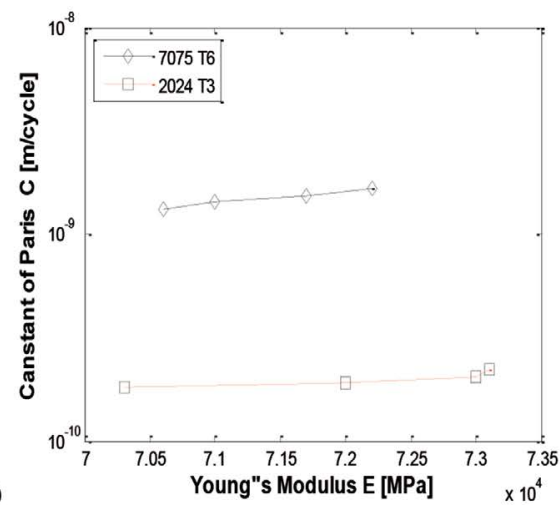

b)

Fig. 10. Constant $C$ of Paris law versus, a) yield strength, b) Young's modulus 


\section{CONCLUSION}

This paper focuses a contribution in development of analytical model for fatigue crack growth in Paris stage as a function of different materials properties (Yield strength, Young's modulus and cyclic hardening parameters) based on the cyclic plastic deformation at the crack tip. The experimental data are presented in this paper for the validation of the developed model.

The main advantage of the developed model over the literature model is the direct dependence of the Paris law constants $(C$ and $m)$ on mechanical properties and hardening parameters. Also, a separate parameter is included in the Paris law characterized by the constant (b) depending only on the hardening parameter $(n ')$ and the ratio $(a / w)$ used in the correction function of geometry specimen (see equations 15 and 16). The developed model is applied to stable stage (Paris region) comparatively to other models such as Duggan, Forman and Tzamtzis models, which include the instable stage of crack growth.

Thus, from this study, the mechanical properties and hardening parameters effects are investigated on fatigue crack growth rate and the following conclusions can be drawn:

- The experimental data use for validation is enclosed by the developed model with good agreement.

- The fatigue crack growth rate increase in an increasing the hardening parameter $\left(K^{\prime}\right)$ and their effect is shown clearly in the evolution of constant $(C)$ in the Paris law.

- The variability of cyclic hardening exponent ( $(n)$ shows a moderate effect on FCGRs where the effect of hardening exponent $\left(n^{\prime}\right)$ is significant on FCGRs of 7075 T6 Al-Alloy comparatively to 2024 T3 Al-Alloy.

- Fatigue crack growth rate increases with deceasing the yield strength.

- Slow increasing of FCGRs is noticed with a decreasing in Young's modulus.

- The constants $(C, m)$ of the Paris law depend strongly on the cyclic hardening exponent. 


\section{REFERENCES}

[1] N. Vikram and R. Kumar, "Review on fatigue-crack growth and finite element method," Int. J. Sci. Eng. Res., vol. 4, no. 4, pp. 833-843, 2013.

[2] F. Bergner, G. Zouhar, and G. Tempus, "The material-dependent variability of fatigue crack growth rates of aluminium alloys in the Paris regime," Int. J. Fatigue, vol. 23, pp. 383-394, 2001.

[3] J. H. Melson, "Fatigue crack growth analysis with finite element methods and a monte carlo simulation," Thesis Master, Faculty of the Virginia Polytechnic Institute, 2014.

[4] T. Mann, "The influence of mean stress on fatigue crack propagation in aluminium alloys," Int. J. Fatigue, vol. 29, no. 8, pp. 1393-1401, 2007.

[5] A. E. M. Alaoui, "Influence du chargement sur la propagation en fatigue de fissures courtes dans un acier de construction navale," Thesis Doctor, University of Metz, 2005.

[6] K. Alrubaie, E. Barroso, and L. Godefroid, "Fatigue crack growth analysis of pre-strained 7475-T7351 aluminum alloy," Int. J. Fatigue, vol. 28, no. 8, pp. 934-942, Aug. 2006.

[7] J.-K. Kim and D.-S. Shim, "The variation in fatigue crack growth due to the thickness effect," Int. J. Fatigue, vol. 22, pp. 611-618, 2000.

[8] J. R. Mohanty, B. B. Verma, and P. K. Ray, "Prediction of fatigue crack growth and residual life using an exponential model: Part I (constant amplitude loading)," Int. J. Fatigue, vol. 31, pp. 418-424, 2009.

[9] J. C. Newman, "The merging of fatigue and fracture mechanics concepts: a historical perspective," Prog. Aerosp. Sci., vol. 34, no. 5-6, pp. 347-390, 1998.

[10] M. Vormwald, "Fatigue crack propagation under large cyclic plastic strain conditions," Procedia Mater. Sci., vol. 3, pp. 301-306, 2014.

[11] P. Johansingh, C. Mukhopadhyay, T. Jayakumar, S. Mannan, and B. Raj, "Understanding fatigue crack propagation in AISI $316(\mathrm{~N})$ weld using Elber's crack closure concept: Experimental results from GCMOD and acoustic emission techniques," Int. J. Fatigue, vol. 29, no. 12, pp. 2170-2179, Dec. 2007.

[12] M. Vormwald, "Effect of cyclic plastic strain on fatigue crack growth," Int. J. Fatigue, pp. 1-9, 2015.

[13] K. Prasad, V. Kumar, K. Bhanu Sankara Rao, and M. Sundararaman, "Effects of crack closure and cyclic deformation on thermomechanical fatigue crack growth of a Near $\alpha$ Titanium Alloy," Metall. Mater. Trans. A, vol. 47A, no. 7, pp. 37133730, Jul. 2016.

[14] H. L. Ewalds, "The effect of environment on fatigue crack closure in Aluminium alloys," Eng. Fract. Mechamics, vol. 13, pp. 1001-1006, 1980.

[15] J. R. Lloyd, "The effect of residual stress and crack closure on fatigue crack growth," University of Wollongong Thesis Collection, 1999. 
[16] L. Lawson, E. Y. Chen, and M. Meshii, "Near-threshold fatigue: a review," Int. J. Fatigue, vol. 21, pp. 15-34, 1999.

[17] P. Pao, H. Jones, S. Cheng, and C. Feng, "Fatigue crack propagation in ultrafine grained Al-Mg alloy,” Int. J. Fatigue, vol. 27, no. 10-12, pp. 1164-1169, Oct. 2005.

[18] T. Hanlon, E. D. Tabachnikova, and S. Suresh, "Fatigue behavior of nanocrystalline metals and alloys," Int. J. Fatigue, vol. 27, no. 10-12, pp. 1147-1158, 2005.

[19] K. Pandey and S. Chand, "An energy based fatigue crack growth model," Int. J. Fatigue, vol. 25, no. 8, pp. 771-778, Aug. 2003.

[20] P. J. Huffman, "A strain energy based damage model for fatigue crack initiation and growth,” Int. J. Fatigue, vol. 88, pp. 197-204, 2016.

[21] N. W. Klingbeil, "A total dissipated energy theory of fatigue crack growth in ductile solids," Int. J. Fatigue, vol. 25, pp. 117-128, 2003.

[22] S. C. Wu, Z. W. Xu, C. Yu, O. L. Kafka, and W. K. Liu, “A physically short fatigue crack growth approach based on low cycle fatigue properties," Int. J. Fatigue, vol. 103, pp. 185-195, Oct. 2017.

[23] A. Noroozi, G. Glinka, and S. Lambert, "A two parameter driving force for fatigue crack growth analysis," Int. J. Fatigue, vol. 27, no. 10-12, pp. 1277-1296, Oct. 2005.

[24] A. Noroozi, G. Glinka, and S. Lambert, "A study of the stress ratio effects on fatigue crack growth using the unified two-parameter fatigue crack growth driving force," Int. J. Fatigue, vol. 29, no. 9-11, pp. 1616-1633, 2007.

[25] R. C. Dimitriu and H. K. D. H. Bhadeshia, "Fatigue crack growth rate model for metallic alloys," Mater. Des., vol. 31, pp. 2134-2139, 2010.

[26] J. C. Radon, "A model for fatigue crack growth in a threshold region," Int. J. Fatigue, vol. 4, no. 3, pp. 161-166, 1982.

[27] K. M. Lal and S. B. L. Garg, "A fatigue crack propagation model for strain hardening materials," Eng. Fract. Mechamics, vol. 9, pp. 939-949, 1977.

[28] B. Tomkins, "Fatigue crack propagation - an analysis," Phil Mag, vol. 18, no. 155, pp. 1041-1066, 1968.

[29] N. A. Fleck, K. J. Kang, and M. F. Ashby, "The cyclic properties of engineering materials," Acta Metall. Materalia, vol. 42, pp. 365-381, 1994.

[30] K. K. Shi, L. X. Cai, S. Qi, and C. Bao, "Prediction of fatigue crack growth based on low cycle fatigue properties," Eng. Fract. Mech., pp. 1-18, 2013.

[31] K. K. Shi, L. X. Cai, L. Chen, S. C. Wu, and C. Bao, "A prediction model for fatigue crack growth using effective cyclic plastic zone and low cycle fatigue properties," Int. J. Fatigue, vol. 158, pp. 209-219, Apr. 2016.

[32] A. Tzamtzis and A. T. Kermanidis, "Fatigue crack growth prediction in 2xxx AA with friction stir weld HAZ properties," Frat. ed Integrità Strutt., vol. 35, pp. 396-404, 2016. 
[33] S. K. Paul and S. Tarafder, "Cyclic plastic deformation response at fatigue crack tips,” Int. J. Press. Vessel. Pip., vol. 101, pp. 81-90, 2013.

[34] F. V. Antunes, R. Branco, P. A. Prates, and L. Borrego, "Fatigue crack growth modelling based on CTOD for the 7050-T6 alloy," Fatigue Fract. Eng. Mater. Struct., vol. 40, no. 8, pp. 1309-1320, Aug. 2017.

[35] B. Ould Chikh, A. Imad, and M. Benguediab, "Influence of the cyclic plastic zone size on the propagation of the fatigue crack in case of $12 \mathrm{NC6}$ steel," Comput. Mater. Sci., vol. 43, pp. 1010-1017, 2008.

[36] S. C. Forth, C. W. Wright, and W. M. Johnston, "7075-T6 and 2024-T351 aluminum alloy fatigue crack growth rate data," NASA Cent. Aerosp. Inf., no. 213907, pp. 1-19, 2005.

[37] A. Tzamtzis and A. T. Kermanidis, "Improvement of fatigue crack growth resistance by controlled overaging in 2024-T3 aluminium alloy," Fatigue Fract. Eng. Mater. Struct., vol. 0, pp. 1-13, 2014.

[38] A. Fatemi, A. Plaseied, A. K. Khosrovaneh, and D. Tanner, "Application of bilinear log-log S-N model to strain-controlled fatigue data of aluminum alloys and its effect on life predictions," Int. J. Fatigue, vol. 27, pp. 1040-1050, 2005.

[39] S. Mikheevskiy, "Elastic-plastic fatigue crack growth analysis under variable amplitude loading spectra," Thesis Doctor, University of Waterloo of Canada, 2009.

[40] J. T. P. Castro, Fatigue - Volume II - Propagation of cracks, thermal and stochastic effects. 2009.

[41] J. Colin, "Deformation history and load sequence effects on cumulative fatigue damage and life predictions," Thesis Doctor, University of Toledo Digital Repository, 2010.

[42] A. Saoudi, "Prédiction de la rupture par fatigue dans les pièces automobiles en alliages aluminium," Thesis Doctor, University of Quebec of Chicoutimi, 2008.

[43] A. H. Noroozi, G. Glinka, and S. Lambert, "Prediction of fatigue crack growth under constant amplitude loading and a single overload based on elasto-plastic crack tip stresses and strains," Eng. Fract. Mech., vol. 75, no. 2, pp. 188-206, 2008 .

[44] ASTM E 647-00, "Standard test method for measurement of fatigue crack growth rates," ASTM Int., vol. 3, pp. 1-43, 2001.

[45] C. Jingjie, H. Yi, D. Leilei, and L. Yugang, "A new method for cyclic crack-tip plastic zone size determination under cyclic tensile load," Eng. Fract. Mech., vol. 126, pp. 141-154, 2014.

[46] D. Chen, K. Shirato, M. W. Barsoum, T. El-Raghy, and R. O. Ritchie, "Cyclic fatigue-crack growth and fracture properties in Ti3SiC2 ceramics at elevated temperatures," J. Am. Ceram. Soc., vol. 84, pp. 2914-2920, 2001. 
[47] F. Khelil, B. Aour, M. Belhouari, and N. Benseddiq, "Modeling of fatigue crack propagation in aluminum alloys using an energy based approach," Eng. Technol. Appl. Sci. Res., vol. 3, pp. 488-496, 2013.

[48] S. Ray and J. M. C. Kishen, "Energy based fatigue crack propagation model for plain concrete," Fract. Mech. Concr. Concr. Struct., vol. 8, pp. 978-989, 2010.

[49] S. B. Chakrabortty, "A model relating low cycle fatigue properties and microstructure to fatigue crack propagation rates," Fatigue Eng. Mater. Struct., vol. 2, pp. 331-344, 1979.

[50] J. Wasé and E. Heier, "Fatigue crack growth thresholds - the influence of Young's modulus and fracture surface roughness," Int. J. Fatigue, vol. 20, no. 10, pp. $737-$ $742,1998$.

[51] S. Groh, S. Olarnrithinun, W. A. Curtin, A. Needleman, V. S. Deshpande, and E. Van der Giessen, "Fatigue crack growth from a cracked elastic particle into a ductile matrix," Philos. Mag., vol. 88, no. 30-32, pp. 3565-3583, Oct. 2008.

[52] Y. Xiang, Z. Lu, and Y. Liu, "Crack growth-based fatigue life prediction using an equivalent initial flaw model. Part I: Uniaxial loading," Int. J. Fatigue, vol. 32, no. 2, pp. 341-349, 2010.

[53] M. Ndiaye, S. Gaye, Z. Azari, and G. Pluvinage, "Propagation de fissures en fatigue par chocs," J. des Sci., vol. 6, no. 1, pp. 22-29, 2006.

[54] B. Ould Chikh, J. M. N. A. Imad, and M. Benguediab, "Influence de la variabilité des paramètres de la relation de Paris sur la prédiction de la durée de vie en fatigue," vol. 4, pp. 27-31, 2007.

[55] Z. Gao, W. Sun, Y. Wang, and F. Zhang, "Fatigue crack growth properties of typical pressure vessel steels at high temperature," in 18th International Conference on Structural Mechanics in Reactor Technology, 2005, pp. 1754-1761. 